\title{
EXPERIMENTAL STUDY OF FLEXURAL BEHAVIOUR OF LAYERED STEEL FIBRE REINFORCED CONCRETE BEAMS
}

\author{
Inmaculada MARTÍNEZ-PÉREZ ${ }^{\mathrm{a}}$, Juozas VALIVONIS ${ }^{\mathrm{b}}$, Remigijus ŠALNA ${ }^{\mathrm{b}}$, \\ Alfonso COBO-ESCAMILLA ${ }^{\mathrm{c}}$ \\ ${ }^{a}$ Department of Architectural Construction, School of Building Engineering, \\ Technical University of Madrid, Av. Juan de Herrera 6, 28040 Madrid \\ ${ }^{b}$ Department of Reinforced Concrete and Masonry Structures, Vilnius Gediminas Technical University, \\ Sauletekio al. 11, LT-10233 Vilnius, Lithuania \\ ${ }^{c}$ Department of Building Technology, School of Building Engineering, \\ Technical University of Madrid, Av. Juan de Herrera 6, 28040 Madrid
}

Received 09 Feb 2017; accepted 06 Apr 2017

\begin{abstract}
The building of structures from steel fibre reinforced concrete (SFRC) in the external and conventional reinforced concrete $(\mathrm{RC})$ in the internal layer represents an economical alternative of structures effectively using SFRC. The paper presents test results of flexural behaviour of layered beams with SFRC external layers and RC internal layer. The behaviour of these beams is compared to test results of SFRC and conventional RC beams. The test results show, that the flexural load capacity for all series of beams is nearly similar, but the deflections of layered beams are less comparing to monolithic ones. It also been shown that the equations indicated in the Eurocode 2 can be used to design the flexural reinforcement in layered SFRC beams.
\end{abstract}

Keywords: layered beams, reinforced concrete, steel fibre, flexural behaviour, crack, ductility, stiffness.

\section{Introduction}

The wide use of steel fibre to the concrete matrix substantially change the properties of the base materials, increasing its ductility and flexural strength and improving crack control (ACI Committee 544 1996; Banthia, Sappakittipakom 2007; Wang et al. 2008; Altun et al. 2007). In many cases, the fibres are used in structural applications along with traditional reinforcement, partially or totally replacing them. The steel fibre reinforced concrete (SFRC) fails when the fibres reach ultimate strength or when they lose anchoring properties in the concrete matrix and fail from slip deformations. This failure mode represents the typical and desirable rupture in SFRC (Singh et al. 2004).

The compression strength of a concrete is only slightly affected by the volume of fibres (Kaltakci et al. 2007; Yazici et al. 2007; Rizzuti, Bencardino 2014; Marčiukaitis et al. 2011). Some researchers have reported increases in strength varying from $0 \%$ to $15 \%$ for a $1.5 \%$ fibre volume (Johnston 1984; Williamson 1974). In other cases, small decreases in compression strength have been detected (Turmo et al. 2008; Altun, Haktanir 2004). In all cases, the strength can be significantly increased, when the steel fibres have formed (hooked) ends (Turmo et al.
2008). Some researches noted increases in compression strength, the modulus of elasticity and the Poisson coefficient not greater than $10 \%$ in concretes with compression strength characteristics from $35 \mathrm{MPa}$ to $85 \mathrm{MPa}$ and steel fibre content with formed ends of the $1.5 \%$ total volume. The greater compression strength of SFRC could be very useful in preventing structures from sudden failure due to static loads or dynamic loads (Wang et al. 2011). This improvement is caused by chaotic distribution of steel fibres in concrete matrix restricting deformation of the concrete and significantly improving the ductility (Kaltakci et al. 2007; Blaszczynki, Przybylska-Falek 2015).

The tensile strength of SFRC is generally the same as that of non-reinforced concrete -2 to $4 \mathrm{MPa}$. Nevertheless, its strength could be one or two orders greater. This is firstly due to the amount of energy absorbed by the friction and bending of the fibres where there is a tendency to pull out on both sides of the crack, and secondly the deformation in the fibres that restrict the cracks together (Shah et al. 1978; Visalvanich, Naaman 1983; Gopalaratnam, Shah 1987).

The influence of steel fibres in flexural behaviour is much greater comparing to compression due to the duc-

Corresponding author: Inmaculada Martínez-Pérez

E-mail: i.martinez@upm.es 
tile behaviour of SFRC in the area of the stress rupture, with the development of residual strength after the cracking of the concrete (Marar et al. 2001; Nelson et al. 2002; Paine et al. 2002). Depending on the volume and type of steel fibre added, the post-cracking behaviour of the concrete can result in strength levels that exceed those of the cracking, with great ductility (Johnston 1980; Taheri et al. 2012; Vandewalle 2000; Abas et al. 2013; Lin et al. 2014a, 2014b). A volume of steel fibres of less than $0.5 \%$ can have a negative effect on the static strength. As a consequence of the high post-cracking residual strength of SFRC, the use of this material offers huge advantages in applications such as elevated steel fibre reinforced concrete slabs (E-SFRC) (Salehian, Barros 2015; Sasani, Sagiroglu 2008).

The test results of other authors show (Williamson 1978), that SFRC can increase shear capacity of beams. In conventionally reinforced beams $(305 \times 546 \times 7010 \mathrm{~mm})$, with $1.66 \%$ straight steel fibre volume, shear capacity can be increased by $45 \%$. When the steel fibres with deformed ends were used (1.1\% volume), shear capacity increased between $45 \%$ and $67 \%$ and beams failed on bending. It's even show that, in some cases, SFRC can replace shear reinforcement. The test results also demonstrate that in SFRC beams there is a significant increase in ductility in terms of shear capacity (Turmo et al. 2008; Ding et al. 2011; Yazdanbakhsh et al. 2015; Amin, Foster 2016).

The characteristics of the steel fibre give it extraordinary ductility after cracking in the concrete matrix. The ductility depends on the type, anchoring properties and volume of fibre used (Johnston 1974; Anderson 1978; Johnston 1982). The significant effect can be reached; the fibres have a crimped, waved, deformed surfaces shapes or hooked ends. These fibres are more effective than their straight, uniform equivalents with the same length and diameter (Brandshaug et al. 1978; Johnston 1984).

The test results of other authors (Hannant 1984) shows that steel fibres have a minor effect on the shrinkage of SFRC. Nevertheless, when shrinkage is restricted, the tests show that, cylindrical test tubes of concrete placed around a steel ring, significantly reduced a cracking. At the same time, it should be noted that creep tests carried out during compression testing over a 12-month period reveal that the steel fibre does not reduce SFRC creep deformation.

As can be seen above, the use of SFRC in structures offers undoubted advantages with respect to conventional concrete (RC). Unfortunately, the SFRC is more expensive. One possibility of an economical solution is the construction of layered beams and slabs, where the top and bottom layers produces from SFRC, and middle (internal) layer - from conventional RC. The top and bottom (external) layers have to resist greater tension and compression stresses and to decrease cracking. That is why these are the areas, where SFRC is most needed. The middle (internal) layer is not so significant in such structures than the top and bottom layers. Here, the advantages of using SFRC are less important.

The use of this strategy has been successfully substantiated experimentally in multi-layer beams and slabs manufactured from RC and light concrete (LC) (Juknevicius et al. 2006; Mouritz, Thompson 1999; Marciukaitis, Juknevicius 2002). In this case, RC is used on the external layers and LC in the middle (internal). This offers the advantage of greater thermal insulation through the use of LC, compatible with the normal strength of RC on the outside layers. However, information regarding the behaviour of multi-layer beams made from SFRC is very pure. Satisfactory results have been obtained from experiments on dual-layer SFRC and RC beams and slabs, although apparently, there has been no research into the behaviour of three-layer structures.

The main aim of this research is to analyse the flexural behaviour of multi-layer beams, which use SFRC on the external layers and conventional $\mathrm{RC}$ - in the internal one. This paper presents test program of two types of layered beams, subjected for flexure. The test results of layered beams are compared with the test results of conventional monolithic RC and SFRC beams.

\section{Testing programme}

8 beams of $3000 \mathrm{~mm}$ length, $150 \mathrm{~mm}$ width and $300 \mathrm{~mm}$ height were produced in testing program. The composition of SFRC and RC is presented in Table 1. The Portland cement of 42.5 class with $2.1 \mathrm{~kg} / \mathrm{m}^{3}$ of plasticiser were used producing the concrete.

Table 1. Consistence of concrete used

\begin{tabular}{lccccc}
\hline & $\begin{array}{c}\text { Cement } \\
\left(\mathrm{kg} / \mathrm{m}^{3}\right)\end{array}$ & $\begin{array}{c}\text { Gravel } \\
\left(\mathrm{kg} / \mathrm{m}^{3}\right)\end{array}$ & $\begin{array}{c}\text { Sand } \\
\left(\mathrm{kg} / \mathrm{m}^{3}\right)\end{array}$ & $\begin{array}{c}\mathrm{W} / \mathrm{C} \\
\left(\mathrm{kg} / \mathrm{m}^{3}\right)\end{array}$ & $\begin{array}{c}\text { Steel fibers } \\
\left(\mathrm{kg} / \mathrm{m}^{3}\right)\end{array}$ \\
\hline $\mathrm{RC}$ & 350 & 980 & 920 & 0.5 & - \\
SFRC & 350 & 980 & 920 & 0.5 & 30 \\
\hline
\end{tabular}

The steel fibres, used in testing programme is manufactured by Bekaert ${ }^{\circledR}$ under the commercial name Dramix ${ }^{\circledR} 55 / 30 \mathrm{~B} \mathrm{G}$, with a length of $30 \mathrm{~mm}$ and a diameter of $0.55 \mathrm{~mm}$, a length diameter ratio was equal to 55 .

In order to analyse the behaviour of layered beams and to compare the test results with conventional elements, the three types of elements were produced: two monolithic RC beams (beams 1 and 2, referred to as RC); two types of layered beams with different height of external layers - beams with $50 \mathrm{~mm}$ and with $100 \mathrm{~mm}$ external SFRC layers (beams 3 and 4, referred to as MC1 and beams 5 and 6 , referred to as $\mathrm{MC} 2$, respectively). The last series consist of two monolithic SFRC beams (position 7 and 8 , referred as SFRC).

The concreting process was as follows: the monolithic beams of series RC and SFRC were only concreted in one time.

In the case of the layered beams, the bottom external layers of SFRC were firstly concreted. Three days later, 


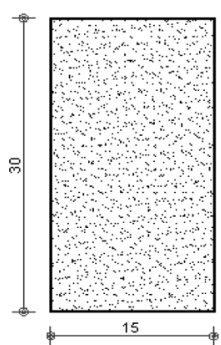

$\mathrm{RC}$

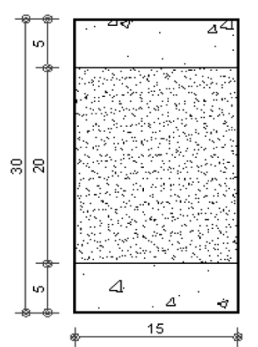

MC1

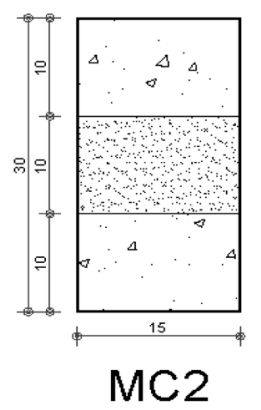

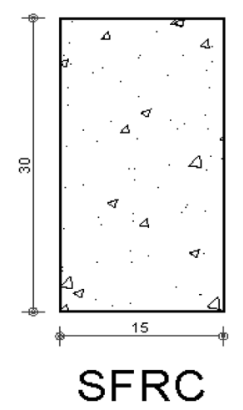

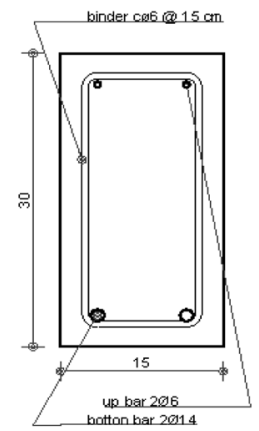

Fig. 1. Cross-section and reinforcement of the tested beams

the internal RC layers were concreted and after a further three days, the beams were finished with the top SFRC layer. The different tiers of layered beams were concreting with technological breaks. The aim of such concreting technology was to evaluate the influence of bond connection between layers on behaviour and failure character imitating real concreting conditions.

There were not connectors placed between the layers. It was assumed, that the chemical and mechanical bond between will be improved.

All beams were reinforced in the same way. Longitudinal reinforcement consists of two $\varnothing 14 \mathrm{~mm}$-diameter Bst500B (S500) steel bars. The shear reinforcement (2Ø6, S500) was designed to ensure that beam failure was due to bending earlier than shear. The cross-section and reinforcement of the tested beams is presented in Figure 1.

In order to determine the mechanical characteristics of the steel used in the experiment, three specimens (bars) were tested. Average $563 \mathrm{MPa}$ yield strength and $200 \mathrm{GPa}$ modulus of elasticity was determined during the tests.

In order to determine the mechanical characteristics of the concrete, three etalon cylinders (dimensions $300 \mathrm{~mm}$ by $150 \mathrm{~mm}$ ) were tested. The average compression strength was $33.29 \mathrm{MPa}$ for the $\mathrm{RC}$ and $35.26 \mathrm{MPa}$ for the SFRC.

\section{Results and analysis}

The beams were tested to failure applying typical four points bending test scheme. The span between supports was $2500 \mathrm{~mm}$, shear span - one third the span. A universal compression machine $\mathrm{W}+\mathrm{B}$ LFV 5000 was used with the controlled loading speed $(0.02 \mathrm{~mm} / \mathrm{s})$. An "Almemo" displacement transducer was used during testing. The production and testing of all beams was carried out at the Laboratory of the Department of Reinforced Concrete and Masonry Structures at Vilnius Gediminas Technical University.

The Figure 2 presents load-deflection curves of the eight tested beams. It can be seen that all beams have a very similar character of behaviour. It should be noted that there is no horizontal slip between the layers registered. The behaviour of all beams in elastic stage before cracking is also very similar. The cracking force in all cases was observed below $23 \mathrm{kN}$. Next, stiffness after elastic stage drops off sharply due to the cracking in the concrete in the part of the beam in pure bending zone; however the diagram shows highly linear behaviour until the point of steel yielding when the load varies from $100 \mathrm{kN}$ to $120 \mathrm{kN}$. After yielding of the steel, the beam continues to deform with smaller load increase. Finally, failure occurs due to the plastic hinge of concrete compression zone. The differences between the loads corresponding the yielding and strength limits of all beams are very small. However, there are important differences of behaviour and failure character of all types of the beams (Fig. 3).

Table 2 shows for the cracking of the concrete, the yielding point of the steel, and for the carrying capacity and descending branch loads points. The values corresponding to the cracking, yielding, carrying capacity and descending branch moments $(\mathrm{m})$, the deflections of the beams $(d)$, the stiffness $(k)$ of the cracking stage section (the stiffness of the yielding stage section has been

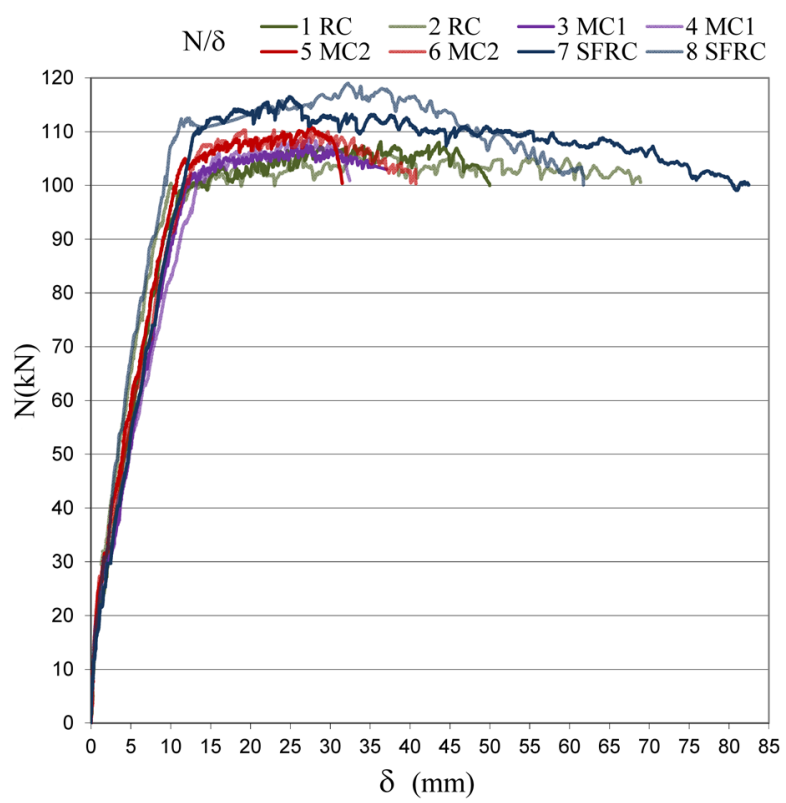

Fig. 2. Load-deflection curves of the eight tested beams 


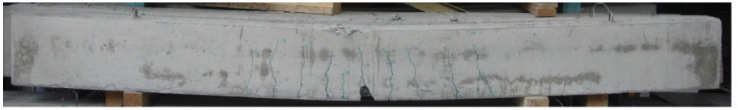

$1 \mathrm{RC}$

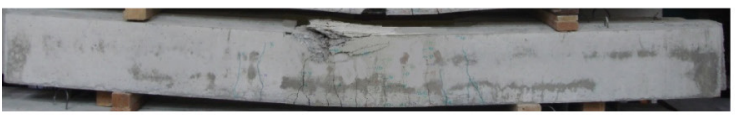

$2 \mathrm{RC}$

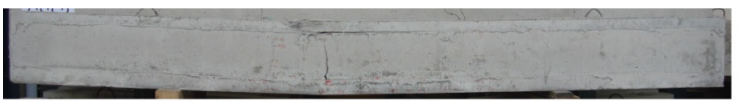

$3 \mathrm{MC} 1$

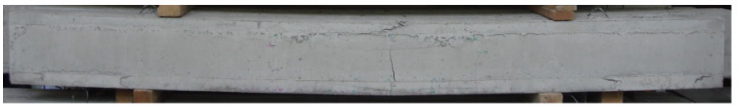

$4 \mathrm{MCl}$

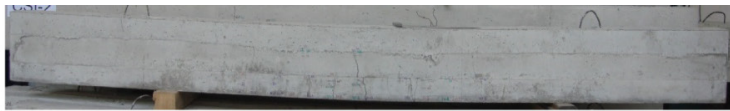

$5 \mathrm{MC} 2$

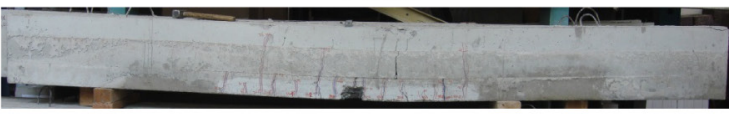

$6 \mathrm{MC} 2$

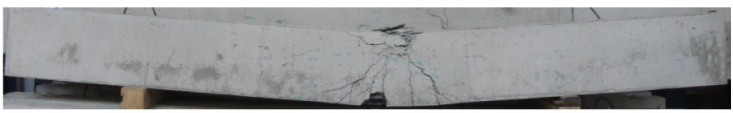

7 SFRC

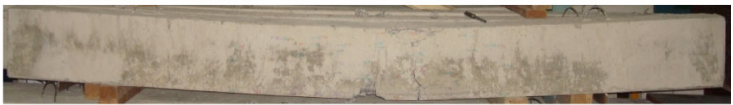

8 SFRC

Fig. 3. Failure point of the tested beams
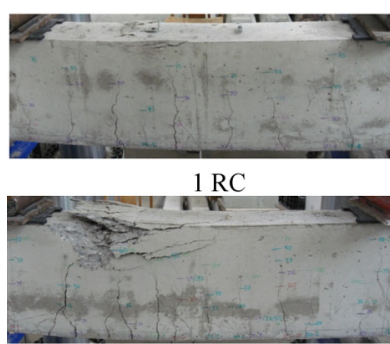

$2 \mathrm{RC}$
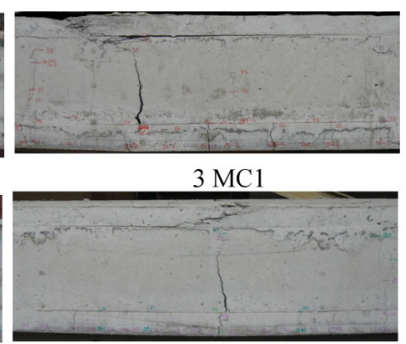

$4 \mathrm{MC} 1$

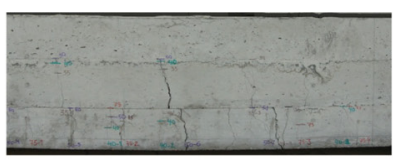

$5 \mathrm{MC} 2$

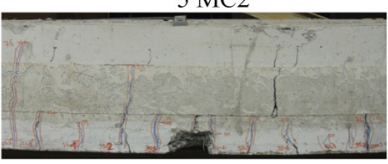

$6 \mathrm{MC} 2$

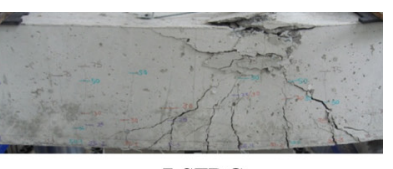

7 SFRC

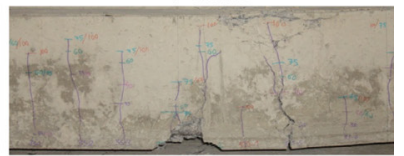

8 SFRC

Fig. 4. Cracking layout on the beams tested

evaluated as an average value, considering that the section showed a linear behaviour pattern between yielding and cracking points) and the areas $(a)$ between each section, or energy absorbed, representing an average of the beam ductility.

The analysis of Figure 3 and Table 2 shows that the behaviour is very ductile, especially between cracking and yielding stages. It caused by low reinforcement volume of longitudinal reinforcement $\left(\rho_{1}=0.06\right)$ and influence of steel fibres on stiffness of external layers. The

Table 2. Results obtained from flexural testing layout and width of cracks are also different. The character of layout of cracks in layered beams was influenced by stiffness of bond between layers. Due to the horizontal cracks (Fig. 4) between bottom and internal layer in tested beams, the shear strains between layers occurred. It shows that layers slipped between each other. This slip deformation is a cause character of cracks. Besides, the external layer was reinforced by longitudinal reinforcement, and internal not. The difference of reinforcement volume and slip (shear) deformation between layers caused the crack's layout in internal layer is less.

\begin{tabular}{|c|c|c|c|c|c|c|c|c|c|c|c|c|c|c|c|}
\hline & \multicolumn{4}{|c|}{ Cracking } & \multicolumn{4}{|c|}{ Yielding } & \multicolumn{3}{|c|}{ Carrying capacity } & \multicolumn{3}{|c|}{ Descending branch } \\
\hline & & $\begin{array}{c}m, \\
\mathrm{kNm}\end{array}$ & $\begin{array}{c}d, \\
\mathrm{~mm}\end{array}$ & $\begin{array}{c}a, \\
\mathrm{kNmm}\end{array}$ & \begin{tabular}{|c|}
$k$, \\
$\mathrm{kN} / \mathrm{mm}$
\end{tabular} & $\begin{array}{c}m, \\
\mathrm{kNm}\end{array}$ & $\begin{array}{c}d, \\
\mathrm{~mm}\end{array}$ & \begin{tabular}{c|}
$a$, \\
$\mathrm{kNmm}$
\end{tabular} & \begin{tabular}{|c|}
$k$, \\
$\mathrm{kN} / \mathrm{mm}$
\end{tabular} & $\begin{array}{c}m, \\
\mathrm{kNm}\end{array}$ & $\begin{array}{c}d, \\
\mathrm{~mm}\end{array}$ & $\begin{array}{c}a, \\
\mathrm{kNmm}\end{array}$ & $\begin{array}{c}m, \\
\mathrm{kNm}\end{array}$ & $\begin{array}{c}d, \\
\mathrm{~mm}\end{array}$ & $\begin{array}{c}a, \\
\mathrm{kNmm}\end{array}$ \\
\hline \multirow{3}{*}{$\mathrm{RC}$} & 1 & 8.8 & 0.9 & 11 & 23 & 40.8 & 10.9 & 619 & 7.7 & 45 & 36.3 & 2635 & 43.3 & 47.8 & 1218 \\
\hline & 2 & 8.4 & 0.6 & 7 & 31.9 & 41.8 & 10 & 613 & 8.6 & 44.1 & 32.7 & 2314 & 42.3 & 68.7 & 3725 \\
\hline & $\bar{X}$ & 8.6 & 0.7 & 9 & 27.5 & 41.4 & 10.5 & 616 & 8.1 & 44.5 & 34.5 & 2474 & 42.8 & 58.3 & 2471 \\
\hline \multirow{3}{*}{$\mathrm{MC} 1$} & 3 & 9.8 & 1 & 13 & 24.1 & 42.1 & 12.1 & 695 & 7 & 44.7 & 27.1 & 1567 & 43.3 & 35.3 & 863 \\
\hline & 4 & 9.7 & 1 & 13 & 23.4 & 42.8 & 13.6 & 815 & 6.3 & 45.3 & 27.3 & 1453 & 44.3 & 31.1 & 400 \\
\hline & $\bar{x}$ & 9.8 & 1 & 13 & 23.7 & 42.4 & 12.8 & 755 & 6.6 & 45 & 27.2 & 1510 & 43.8 & 33.2 & 631 \\
\hline \multirow{3}{*}{$\mathrm{MC} 2$} & 5 & 9.4 & 0.8 & 8 & 27.9 & 43.7 & 11.8 & 746 & 7.5 & 46.2 & 27.4 & 1677 & 45.4 & 30.1 & 297 \\
\hline & 6 & 10.1 & 1.1 & 18 & 25.5 & 44.8 & 14.1 & 942 & 6.2 & 45.9 & 19.1 & 544 & 43.4 & 38.9 & 2119 \\
\hline & $\bar{x}$ & 9.8 & 0.9 & 13 & 26.7 & 44.3 & 12.9 & 844 & 6.8 & 46.1 & 23.3 & 1110 & 44.4 & 34.5 & 1208 \\
\hline \multirow{3}{*}{ SFRC } & 7 & 9.5 & 1 & 13 & 22.7 & 45.6 & 11.8 & 750 & 8.3 & 48.6 & 23.8 & 1356 & 45.8 & 54.4 & 3396 \\
\hline & 8 & 12.4 & 1.1 & 14 & 22.4 & 46.8 & 11.3 & 764 & 8.6 & 49.5 & 32.3 & 2393 & 47.1 & 61.5 & 3241 \\
\hline & $\bar{x}$ & 11 & 1.1 & 13 & 22.5 & 46.2 & 11.6 & 757 & 8.4 & 49.1 & 28 & 1874 & 46.4 & 57.9 & 3318 \\
\hline
\end{tabular}




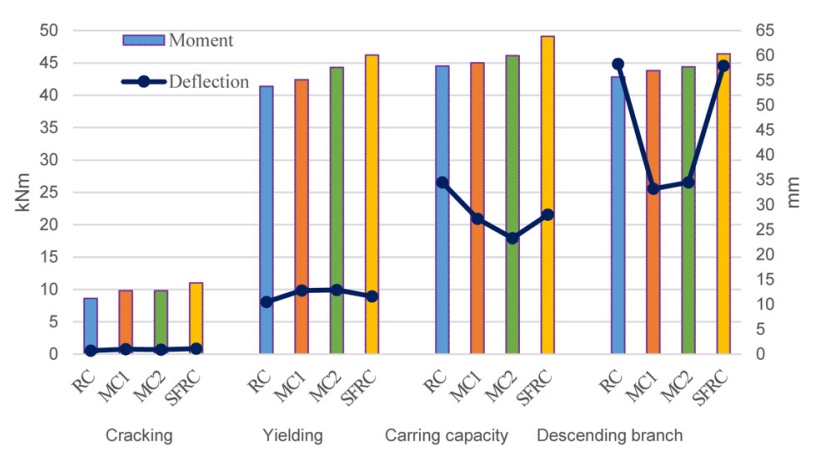

Fig. 5. Comparison of moments and deflections of all beam types tested

In the case of the RC beams, the normal cracks also appeared along its length in pure bending zone, while on SFRC beams, cracks were located more in the centre of the beam, with a length of approximately one and a half times the cross-section depth. It shows that the steel fibres restricts appear of new cracks.

Figure 5 presents the average values of moment and deflection of all beam types in cracking, yielding, carrying capacity and descending branch points.

Analysis of Figure 5 shows, that in all analysed stages (cracking, yielding, carrying capacity and descending branch), the values of the moments obtained increase nearly in line with increase of beam's steel fibre volume. These differences are greater when the cracking and yielding moments are analysed and are less at the carrying capacity as well as at descending branch moments. These results are consistent with those obtained by other researchers looking at beams featuring two SFRC and RC layers in that the yielding moments of the layered beams are less comparing to monolithic SFRC beams. However, analysing deflections in all mentioned stages no clear pattern of behaviour can be seen.

Analysing the deflections on the descending branch, the deflections of layered beams are approximately $43 \%$ less comparing to monolithic beams. Besides deflections of RC and SFRC beams are nearly similar.

Figure 6 presents the average stiffness for each beam types before and after cracking. The analysis of Figure 6

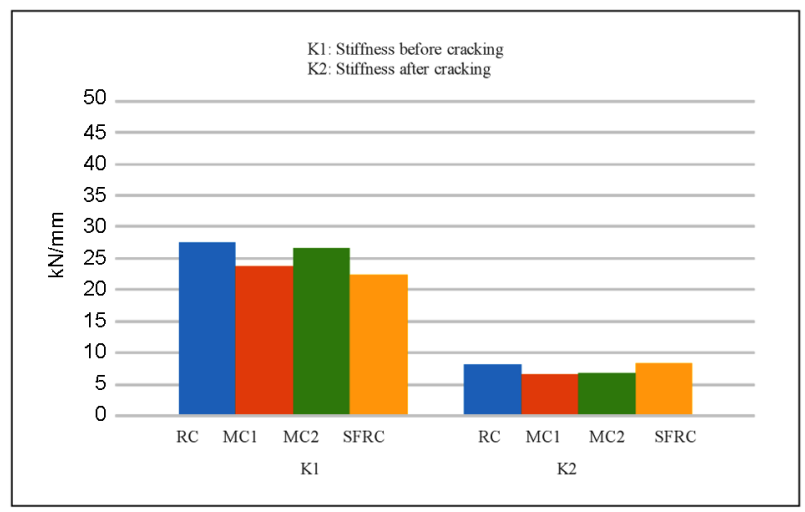

Fig. 6. Average stiffness before and after cracking of beams tested

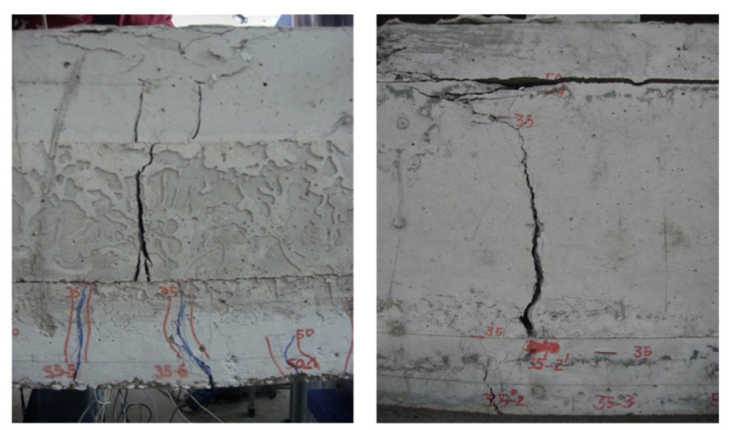

Fig. 7. Cracking layout of middle RC layers of layered beams tested

shows, that after cracking the stiffness of all types of the beams decrease more than two times. Furthermore, the stiffness of the cracked layered beams is $20-25 \%$ less comparing to monolithic beams. This difference can be caused due to the fact that cracking in the middle (internal) RC layer begins before it does in the bottom (external) SFRC layer. It results, the different cracks widths in different layers, which layout is also different.

This layout character of cracks was mainly caused by shear stiffness between bottom external and internal layers. Due to the reason, that the horizontal crack between layers appears and shear strains occurs, the characters of crack layout was changed. Due to the shear strains, the distribution of normal cracks in external (bottom) and internal layers was different. It caused the different distance between cracks in external and internal layers. Therefore, the lay of normal cracks was not a same in different layers (Fig. 7).

Figure 8 presents the relation of average values of energy absorbed in each of the analysed points and bending moment.

The analysis of Figure 8 shows, that energy absorbed in cracking and yielding stages are nearly similar for all types of beams tested. However, the results of energy absorbed after the moment of yielding, comparing the monolithic and layered beams are very different.

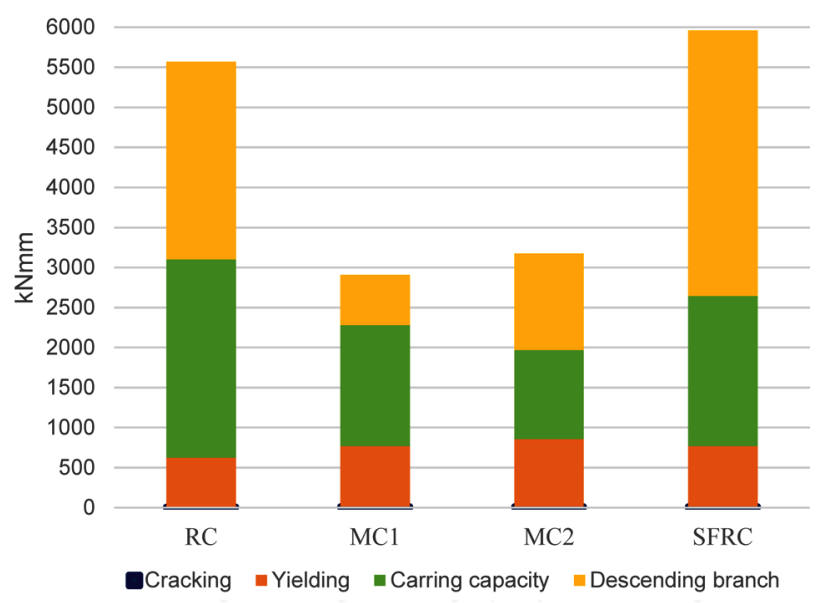

Fig. 8. The relation of energy absorbed and bending moment of beams tested 
The energy absorbed of monolithic beams is significantly greater than layered beams. In the case of between the carrying capacity and descending branch moments, the energy absorbed by the monolithic beams is more than twice greater that absorbed by the layered beams. This pre-supposes that the capacity to absorb energy in monolithic beams is much higher than in layered beams.

Table 3. Ductility values of beams tested

\begin{tabular}{ccccc}
\hline Name of series & $\mathrm{au} / \mathrm{apl}$ & $\mathrm{du} / \mathrm{dpl}$ & $(\mathrm{au} / \mathrm{apl})^{*}$ & $(\mathrm{du} / \mathrm{dpl})^{*}$ \\
\hline $\mathrm{RC}$ & 9 & 5.6 & 1 & 1 \\
$\mathrm{MC} 1$ & 3.8 & 2.6 & 0.4 & 0.5 \\
$\mathrm{MC} 2$ & 3.8 & 2.7 & 0.4 & 0.5 \\
SFRC & 7.9 & 5 & 0.9 & 0.9 \\
\hline
\end{tabular}

Note: $*$ - standardised results

The Table 3 presents evaluation of the ductility of the beams in two different ways - firstly as the ratio between absorbed energy in descending branch stage and in the point of yielding stage of the beam (au/apl). Secondly - the ratio between deflection in descending branch stage and deflection in the point of yielding stage $(\mathrm{du} / \mathrm{dpl})$. The results have also been standardised, taking the values of $\mathrm{RC}$ beams as the point of reference.

The analysis of Table 3 also shows that the results obtained in terms of energy or deflection are very similar due to similarity between the values for the moments evaluated on all beam types during the tests. Furthermore, regardless of the method of evaluating ductility, $\mathrm{RC}$ beams are the most ductile. SFRC beams reach practically the same ductility values as RC beams, while layered beams are almost half this level, due to the lower deflection of such beams.

Table 4 presents the values of the experimental yielding moment (Mpe) and theoretical (according to Eurocode 2 (CEN 2010) yielding moment (Mpt) calculated from the tested beams.

Table 4. Comparison of experimental and theoretical yielding moment of beams tested (average values).

\begin{tabular}{lccc}
\hline & Mpe $(\mathrm{kNm})$ & $\mathrm{Mpt}(\mathrm{kNm})$ & $\mathrm{y}^{*}(\mathrm{~mm})$ \\
\hline $\mathrm{RC}$ & 41.3 & 42.3 & 35 \\
$\mathrm{MC} 1$ & 42.4 & 42.7 & 33 \\
$\mathrm{MC} 2$ & 44.3 & 42.7 & 33 \\
SFRC & 46.2 & 42.7 & 33 \\
\hline
\end{tabular}

Note: *compression zone y calculated according to "EC2"

The analysis of Table 4 shows, that in all cases, where the beams contain SFRC, the theoretical yielding moment and compression zone is the same. The theoretical and test results correspond well. It shows that equations of EC2 for reinforced concrete elements subjected for bending after more deep analysis could be used as well for layered SFRC elements. Besides analysis of beams tested shows that higher than $50 \mathrm{~mm}$ compression layers are not effective for lightly reinforced beams.

\section{Conclusions}

The tests of 8 conventional RC, SFRC and layered beams with different external SFRC layers shows, that load-deflection relationship is very similar. It represents the typical behaviour of lightly reinforced elements, subjected for bending.

The difference, obtained in tests in cracking, yielding, carrying capacity and descending branch stages is very small, in terms of moment values between the 4 different types of beams. The moment values in the four different stages for SFRC beams are higher comparing to the average of layered beams moment values $(12 \%$ in cracking, $7 \%$ in yielding, $8 \%$ in carrying capacity and $5 \%$ in descending branch), which are slightly above those for monolithic RC beams (13\% in cracking, 5\% in yielding, $2 \%$ in carrying capacity and $3 \%$ in descending branch).

The tests of the monolithic beams showed less cracking character than the layered beams. On the RC beams, the cracks were extended the whole length while on the SFRC beams cracking was concentrated mainly in one point, usually near the first crack.

The difference deflection of monolithic and layered beams is significant. Monolithic beams showed greater final deflection, approximately $43 \%$ more, comparing to layered beams. The deflection of monolithic RC beams was greater comparing to monolithic SFRC beams in a $0.7 \%$.

The stiffness of the layered beams is $20-25 \%$ less than that of the monolithic beams due to the cracking in the middle RC layer. It should be taken to account when calculating deflection.

The energy absorbed in the testing by the four types of beams was very similar in the cracking and yielding stages. In the stages of carrying capacity and descending branch, the monolithic beams absorbed significantly greater amount of energy comparing to layered beams. While in descending branch stage MC2, RC and SFRC absorb $91 \%, 292 \%$ and $426 \%$ more than $\mathrm{MC} 1$ respectively, in carrying capacity stage MC1, RC and SFRC absorb $36 \%, 123 \%$ and $69 \%$ more than $\mathrm{MC} 2$, respectively.

Ductility of energy or displacement offers the same results. Approximately the same ductility was released by the monolithic beams, twice from layered beams.

The EC2 equations for calculation of compression zone for SFRC layered beams, subjected for bending shows good agreement with test results. After more deep analysis, it could be suggested for calculation of such elements. It should be noted, that there was not horizontal slip between the layers.

\section{Acknowledgements}

Laboratory of the Department of Reinforced Concrete and Masonry Structures at Vilnius Gediminas Technical University. 


\section{References}

Abas, F. M.; Gilbert, R. I.; Foster, S. J.; Bradford, M. A. 2013. Strength and serviceability of continuous composite slabs with deep trapezoidal steel decking and steel fibre reinforced concrete, Journal of Structural Engineering 49: 866-875.

https://doi.org/10.1016/j.engstruct.2012.12.043

ACI Committee 544. 1996. State of the art report on fiber reinforced concrete. Detroit, USA: American Concrete Institute.

Altun, F.; Haktanir, T. 2004. Comparative experimental study of steel fibre-additive reinforced concrete beams, Materiales de Construcción 54: 5-15.

Altun, F.; Haktanir, T.; Ari, K. 2007. Effects of steel fiber addition on mechanical properties of concrete and RC beams, Construction and Building Materials 21(3): 654-661. https://doi.org/10.1016/j.conbuildmat.2005.12.006

Amin, A.; Foster, S. J. 2016. Shear strength of steel fibre reinforced concrete beams with stirrups, Engineering Structures 11(3): 323-332.

https://doi.org/10.1016/j.engstruct.2015.12.026

Anderson, W. E. 1978. Proposed testing of steel-fibre concrete to minimize unexpected service failures, in Proceedings of RILEM, Symposium of Testing and Test Methods of Fibre Cement Composites, 1978, Sheffield, Lancaster, UK, 223-232.

Banthia, N.; Sappakittipakom, M. 2007. Toughness enhancement in steel fiber hybridization, Cement and Concrete Research 37: 1366-1372. https://doi.org/10.1016/j.cemconres.2007.05.005

Blaszczynki, T.; Przybylska-Falek, M. 2015. Steel fibre reinforced concrete as a structural material, Procedia Engineering 122: 282-289.

https://doi.org/10.1016/j.proeng.2015.10.037

Brandshaug, T.; Ramakrishnan, V.; Coyle, W. V.; Schrader, E. K. A. 1978. Comparative evaluation of concrete reinforced with straight steel fibers and collated fibers with deformed ends. Report No. SDSM\&T-CBS 7801. South Dakota School of Mines and Technology, Rapid City. $52 \mathrm{p}$.

CEN. 2010. Eurocode 2: Design of concrete structures - Pert 1-1: General rules and rules for buildings. Brussels: European Committee for Standardization.

Ding, Y. N.; You, Z. G.; Jalali, S. 2011. The composite effects of steel fibres and stirrups on the shear behaviour of beams using of self-consolidating concrete, Engineering Structures 33(1): 107-117. https://doi.org/10.1016/j.engstruct.2010.09.023

Gopalaratnam, V. S.; Shah, S. P. 1987. Tensile failure of steel fiber reinforced mortar, Journal of Engineering Mechanics 113(5): 635-652. https://doi.org/10.1061/(ASCE)07339399(1987)113:5(635)

Hannant, D. J. 1984. Fibre cements and fibre concretes. Chichester: Wiley \& Sons. 219 p.

Johnston, C. D. 1974. Steel fibre reinforced mortar and concrete - a review of mechanical properties, in Fiber Reinforced Concrete, SP-44, American Concrete Institute, Detroit, 127-142.

Johnston, C. D. 1980. Properties of steel fibre reinforced mortar and concrete, in Proceedings of International Symposium on Fibrous Concrete (CI-80), 1980, Construction Press, Lancaster, 29-47.

Johnston, C. D. 1982. Definitions and measurement of flexural toughness parameters for fiber reinforced concrete, Cement, Concrete and Aggregates 4(2): 53-60. https://doi.org/10.1520/CCA10228J

Johnston, C. D. 1984. Steel fiber reinforced pavement trials, Concrete International: Design \& Construction 6(12): 39-43.
Juknevicius, L.; Marciukaitis, G.; Valivonis, J. 2006. Influence of technological factors on the state of stress and strain in three-layer reinforced concrete structures, Journal of Civil Engineering and Management 12(3): 195-204.

Kaltakci, M. Y.; Arslan, M. H.; Yilmaz, U. S. 2007. The effects of steel fibre reinforced concrete on system ductility, $\mathrm{Ma}$ teriales de Construcción 57: 71-84.

Lin, W.; Yoda, T.; Taniguchi, N. 2014b. Application of SFRC in steel concrete composite beams subjected to hogging moment, Journal of Constructional Steel Research 101: 175-183. https://doi.org/10.1016/j.jcsr.2014.05.008

Lin, W.; Yoda, T.; Taniguchi, N.; Kasano, H.; He, J. 2014a. Mechanical performance of steel concrete composite beams subjected to hogging moment, Journal of Structural Engineering 140(1), 04013031. https://doi.org/10.1061/ (ASCE)ST.1943-541X.0000800

Marar, K.; Eren, O.; Çelik, T. 2001. Relationship between impact energy and compression toughness energy of high-strength fiber-reinforced concrete, Materials Letters 47(4/5): 297304. https://doi.org/10.1016/s0167-577x(00)00253-6

Marciukaitis, G.; Juknevicius, L. 2002. Influence of the internal layer cracks on the cracking of flexural three-layer concrete members, Journal of Civil Engineering and Management 8(3): 153-158. h ttps://doi.org/10.1080/13923730.2002.10531270

Marčiukaitis, G.; Šalna, R.; Jonaitis, B.; Valivonis, J. 2011. A model for strength and strain analysis of steel fiber reinforced concrete, Journal of Civil Engineering and Management 17(1): 137-145. https://doi.org/10.3846/13923730.2011.561521

Mouritz, A. P.; Thompson, R. S. 1999. Compression, flexure and shear properties of a sandwich composite containing defects, Composite Structures 44(4): 263-278. https://doi.org/10.1016/S0263-8223(98)00133-0

Nelson, P. K.; Li, V. C.; Kamada, T. 2002. Fracture toughness of microfiber reinforced cement composites, Journal of Materials in Civil Engineering 14(15): 384-391. https://doi.org/10.1061/(ASCE)0899-1561(2002)14:5(384)

Paine, K. A.; Elliot, K. S.; Peaston, C. H. 2002. Flexural toughness as a measure of shear strength and ductility of prestressed fibre reinforced concrete beams, in Proceedings of the International Congress on Challenges of Concrete Construction, 2002, Dundee, 200-212.

Rizzuti, L.; Bencardino, F. 2014. Effects of fibre volume fraction on the compressive and flexural experimental behaviour of SFRC, Journal of Control Science and Engineering 7(8): 379-390. https://doi.org/10.12988/ces.2014.4218

Salehian, H.; Barros, J. A. O. 2015. Assessment of the performance of steel fibre reinforced self-compacting concrete in elevated slabs, Cement and Concrete Composites 55: 268280. https://doi.org/10.1016/j.cemconcomp.2014.09.016

Sasani, M.; Sagiroglu, S. 2008. Progressive collapse of reinforced concrete structures: a multihazard perspective, $A C I$ Structural Journal 105(1): 95-105.

Shah, S. P.; Stroeven, P.; Dalhuisen, D.; Van Stekelenburg, P. 1978. Complete stress-strain curves for steel fibre reinforced concrete in uniaxial tension and compression, in Testing and Test Methods of Fibre Cement Composites, RILEM Symposium, 1978, Construction Press, Lancaster, 399-408.

Singh, S.; Shukla, A.; Brown, R. 2004. Pullout behaviour of polypropylene fibers from cementitious matrix, Cement and Concrete Research 34(10): 1919-1925. https://doi.org/10.1016/j.cemconres.2004.02.014

Taheri, M.; Barros, J. A. O.; Salehian, H. 2012. Parametric study of the use of strain softening/hardening FRC for RC elements failing in bending, Journal of Materials in Civil Engineering 24(3): 259-274. https://doi.org/10.1061/(ASCE)MT.1943-5533.0000373 
Turmo, J.; Banthia, N.; Gettu, R.; Barragán, B. 2008. Study of the shear behaviour of fibre reinforced concrete beams, Materiales de Construcción 58: 5-15.

Vandewalle, L. 2000. Cracking behaviour of concrete beams reinforced with a combination of ordinary reinforcement and steel fibers, Materials and Structures 33: 164-170. https://doi.org/10.1007/BF02479410

Visalvanich, K.; Naaman, E. A. 1983. Fracture model for fiber reinforced concrete, ACI Journal Proceedings 80(2): $128-138$.

Wang, Z. L.; Liu, Y. S.; Shen, R. F. 2008. Stress-strain relationship of steel fibre reinforced concrete under dynamic compression, Construction and Building Materials 22(5): 811819. https://doi.org/10.1016/j.conbuildmat.2007.01.005

Wang, Z. L.; Shi, Z. M.; Wang, J. G. 2011. On the strength and toughness properties of SFRC under static-dynamic compression, Composites: Part B-Engineering 42: 1285-1290. https://doi.org/10.1016/j.compositesb.2011.01.027
Williamson, G. R. 1974. The effect of steel fibers on the compressive strength of concrete, in Fiber Reinforced Concrete, SP- 44. Detroit: American Concrete Institute, 195207.

Williamson, G. R. 1978. Steel fibers as web reinforcement in reinforced concrete, in Proceedings, U.S. Army Science Conference, West Point, 3: 363-377.

Yazdanbakhsh, A.; Altoubat, S.; Rieder, K. A. 2015. Analytical study of shear strength of macro synthetic fiber reinforced concrete beams, Engineering Structures 100(1): 622-632. https://doi.org/10.1016/j.engstruct.2015.06.034

Yazici, S.; Inan, G.; Tabak, V. 2007. Effect of aspect ratio and volume fraction of steel fiber on the mechanical properties of SFRC, Construction and Building Materials 21(6): $1250-1253$.

https://doi.org/10.1016/j.conbuildmat.2006.05.025

Inmaculada MARTÍNEZ-PÉREZ. Doctor, Associate Professor, Department of Architectural Construction, School of Building Engineering, Universidad Politécnica de Madrid, Av. Juan de Herrera 6, 28040 Madrid. E-mail: i.martinez@upm.es Research interest: concrete TABS, composite structures, reinforced concrete behaviour.

Juozas VALIVONIS. Doctor, Professor, Department of Reinforced Concrete and Masonry Structures. Vilnius Gediminas Technical University (VGTU), Sauletekio al. 11, LT-10223 Vilnius, Lithuania. E-mail: juozas.valivonis@vgtu.lt Doctor (1986). Author of over 50 publications, 2 patented inventions. Research interests: theory of reinforced concrete behaviour, composite structures, reinforced concrete bridges.

Remigijus ŠALNA. Associate Professor, Department of Reinforced Concrete and Masonry Structures, Vilnius Gediminas Technical University. PhD (2008) of Civil Engineering from Vilnius Gediminas Technical University. E-mail: remigijus.salna@vgtu.lt Research interests: mechanics of reinforced concrete, punching shear strength, steel fiber reinforced concrete, probability of building. structures.

Alfonso COBO-ESCAMILLA. Doctor, Professor, Department of Building Technology, School of Building Engineering, Universidad Politécnica de Madrid, Av. Juan de Herrera 6, 28040 Madrid. E-mail: alfonso.cobo@upm.es Author of over 30 JCR publications and 4 books. Research interest: pathology of structures, concrete structures, reinforced concrete behaviour. 